University of South Carolina

Scholar Commons

1998

\title{
$A b$ Initio and DFT Investigations of Lithium/Hydrogen Bonded Complexes of Trimethylamine, Dimethyl Ether and Dimethyl Sulfide
}

\author{
Salai Cheettu Ammal \\ University of South Carolina - Columbia, ammal@cec.sc.edu \\ P. Venuvanalingam
}

Follow this and additional works at: https://scholarcommons.sc.edu/eche_facpub

Part of the Biological and Chemical Physics Commons, and the Physical Chemistry Commons

\footnotetext{
Publication Info

Published in Journal of the Chemical Society, Faraday Transactions, Volume 94, Issue 18, 1998, pages 2669-2674.

(C) Journal of the Chemical Society, Faraday Transactions 1998, Royal Society of Chemistry Ammal, S. S. C. \& Venuvanalingam, P. (1998). Ab initio and DFT investigations of lithium/hydrogen bonded complexes of trimethylamine, dimethyl ether and dimethyl sulfide. Journal of the Chemical Society, Faraday Transactions, 94(18), 2669-2674.

http://dx.doi.org/10.1039/A804601H
}

This Article is brought to you by the Chemical Engineering, Department of at Scholar Commons. It has been accepted for inclusion in Faculty Publications by an authorized administrator of Scholar Commons. For more information, please contact digres@mailbox.sc.edu. 
$A b$ initio and DFT investigations of lithium/hydrogen bonded complexes of trimethylamine, dimethyl ether and dimethyl sulfide

\author{
S. Salai Cheettu Ammal $\dagger$ and P. Venuvanalingam* \\ Department of Chemistry, Bharathidasan University, Tiruchirappalli - 620 024, India
}

Received 17th June 1998, Accepted 24th June 1998

\begin{abstract}
$A b$ initio and DFT computations have been carried out on LiF and HF complexes of a set of n-donors viz. trimethylamine, dimethyl ether and dimethyl sulfide with a $6-31++\mathrm{G}(\mathrm{d}, \mathrm{p})$ basis set. The effect of correlation has been included with MP2, MP4 and DFT calculations. NBO analyses of the wavefunctions have been performed to examine the intermolecular interaction at the orbital level. Calculations reveal that these donors form strong $\mathrm{n} \rightarrow \sigma^{*}$ complexes and computed binding energies of the $\left(\mathrm{CH}_{3}\right)_{2} \mathrm{O} \cdots \mathrm{HF}$ complex agree very well with the experimental binding energies from IR spectroscopy. $\mathrm{LiF}$ forms stronger complexes than $\mathrm{HF}$, and the effect of correlation on the hydrogen bond energy is considerable compared to the lithium bond energy. Though charge transfer interaction contributes to the stability of both LiF and HF complexes, it plays a less dominant role in lithium bonded complexes. While amine and ether donate their $\mathrm{n}_{\sigma}$ lone pair, sulfide donates an $\mathrm{n}_{\pi}$ lone pair and this results in perpendicular intermolecular bonds in sulfide complexes.
\end{abstract}

\section{Introduction}

The existence of mutual attraction and repulsion between closed-shell atoms and molecules is responsible for many phenomena at the molecular level. The hydrogen bond interaction is one among them and has a central place because of its relevance in chemistry and biology. ${ }^{1-7} \mathrm{~A}$ great deal of information has accumulated over the years concerning hydrogen bonding from both experimental and theoretical perspectives. As a result of the investigation of a large number of hydrogen bonded dimers by rotational spectroscopy, Legon and Millen ${ }^{8,9}$ proposed some simple, essentially electrostatic rules for predicting the angular geometries of dimers. In particular, when a base molecule with a lone pair of electrons interacts with a proton donor (HX), at equilibrium the HX molecule lies along the axis of a nonbonding electron pair of the base with the proton pointing towards the lone pair. In more general terms, the most electrophilic site of HX i.e. the $\mathrm{H}$-atom, seeks the most nucleophilic site of the base, but of course the nucleophilic end of HX will avoid this site on the base. This electrostatic approach to hydrogen bonding has received a quantitative interpretation by Buckingham and Fowler $^{10}$ who have used a distributed multipole analysis to predict angular geometries. A donor-acceptor model for the hydrogen bond was first proposed by Mulliken ${ }^{11}$ and later successively applied by many authors.

As the structures of these hydrogen bonded systems have become apparent, the nature of the binding forces has been widely discussed, with questions concerning the balance between 'electrostatic' vs. 'charge transfer' descriptions of the cluster binding. Recently Weinhold and co-workers ${ }^{12,13}$ have shown the importance of donor-acceptor interaction in hydrogen bonding using natural bond orbital (NBO) analysis.

The lithium bond, which appears to be similar to the hydrogen bond has not received much attention in this regard. Though the lithium bond resembles the hydrogen bond in many respects a number of dissimilarities between the two have been noted. ${ }^{14,15}$ We have investigated ${ }^{16}$ a series of lithium as well as hydrogen bonded complexes of various bases using donor-acceptor models based on NBO analysis

$\dagger$ Present address: Department of Materials Chemistry, Graduate School of Engineering, Tohoku University, Aoba - Yama 07, Sendai 980-8579, Japan and discussed the participation of various orbitals in these bonding interactions. In this paper we have chosen a set of three n-donors namely trimethylamine, dimethyl ether and dimethyl sulfide and investigated their interaction with HF and LiF using higher level $a b$ initio and DFT methods. While the case is much simpler with trimethylamine that has only one lone pair, it is rather difficult to decide in ether and sulfide complexes which of the two lone pairs is involved in donation. Specifically, we are trying to resolve this question using NBO analysis.

While there are scant reports on lithium bonded complexes of the n-donors, hydrogen bonded complexes of them have been well studied using theory and experiment. Legon and coworkers undertook a series of investigations ${ }^{17-22}$ on the structure of the complexes of hydrogen halides with trimethylamine using microwave spectroscopy. Latajka and co-workers ${ }^{23,24}$ have reported $a b$ initio studies of the complexes of amines with $\mathrm{HCl}, \mathrm{HBr}$ and $\mathrm{HI}$. A combined photoelectron spectroscopy and $a b$ initio investigation of the complexes of HF with dimethyl ether and dimethyl sulfide have been carried out by Carnovale et al. ${ }^{25} \mathrm{LiF}$ complexes of ammonia and water have been investigated theoretically by few authors ${ }^{26-31}$ and Ault and Pimental ${ }^{32}$ have provided structures of $\mathrm{H}_{3} \mathrm{~N} \cdots \mathrm{LiCl}$ and $\mathrm{H}_{3} \mathrm{~N} \cdots \mathrm{LiBr}$ by studying the vibrations of these complexes isolated in inert matrices. $\mathrm{Li}^{+}$affinity of dimethyl ether has been reported by Abboud et al., ${ }^{33}$ Blint, ${ }^{34}$ and also by Smith et al. ${ }^{35}$ Woodin and Beauchamp ${ }^{36}$ have studied the $\mathrm{Li}^{+}$affinity of trimethylamine and dimethyl ether. We present here an $a b$ initio and DFT computational study of $\mathrm{LiF} / \mathrm{HF}$ complexes with the above lone pair donors, and compare our results with the available experimental values.

\section{Computational details}

Different possible structures for the title complexes have been proposed based on the direction of the lone pairs of the basic atoms. For the trimethylamine complex, only one structure with $C_{3 \mathrm{v}}$ symmetry (I) with $\mathrm{HF} / \mathrm{LiF}$ lying on the $C_{3}$ axis with the proton/lithium pointing towards the lone pair is possible. Three different structures (II, III and IV) have been considered for the complexes of dimethyl ether and dimethyl sulfide; structure II has $C_{2 \mathrm{v}}$ symmetry in which the $\mathrm{HF} / \mathrm{LiF}$ molecular axis is collinear with the $C_{2}$ axis of the donor. Structures III and IV have lower symmetry $\left(C_{\mathrm{s}}\right)$ where the molecular axis of 
$\mathrm{HF} / \mathrm{LiF}$ makes an angle with the $C_{2}$ axis and lies in the molecular plane (III) or in the bisecting plane (IV). In total we have 14 trial geometries, 7 for $\mathrm{LiF}$ complexes and 7 for $\mathrm{HF}$ complexes.

All the above structures have been fully optimized at the Hartree-Fock level with a $6-31++\mathrm{G}(\mathrm{d}, \mathrm{p})$ basis set within their symmetry constraints; frequency calculations have been carried out on the optimized geometries to characterize the stationary points obtained. Geometry optimizations with the above basis set at Møller-Plesset perturbation at the second term level (MP2) and at the density functional theory (DFT) level have been carried out only for the HF stable structures. DFT calculations have been carried out with the exchange potential of Becke $^{37}$ and correlation functional of Lee, Yang and Parr $^{38}$ (B3LYP). Single-point energy calculations at the MP4 (SDTQ) level have also been performed on the MP2 geometries for dimethyl ether and dimethyl sulfide complexes. The interaction energies of the complexes calculated at the HF level are corrected for both basis set superposition error (BSSE) and zero-point vibrational energy (ZPE) and those calculated at DFT, MP2 and MP4 levels are corrected only for BSSE. BSSE has been calculated using the Boys-Bernardi counterpoise method ${ }^{39}$ and by applying a modification ${ }^{40}$ that takes into consideration the relaxation of the monomers upon complexation. The nature of the interactions at the orbital level has been studied using NBO analysis ${ }^{41}$ on the stable structures at all the levels employed with a $6-31++G(d, p)$ basis set. All the above calculations have been performed using the GAUSSIAN 94W program $^{42}$ implemented on a Pentium computer.

\section{Results and discussion}

The results are discussed under the following four subheadings: potential energy surfaces (PES), energetics; structure and bonding; and analysis of interactions. Each section starts with the discussion on $\mathrm{LiF}$ complexes, followed by $\mathrm{HF}$ complexes and ends with the comparison between these two complexes.

\section{Potential energy surfaces}

$\left(\mathrm{CH}_{3}\right)_{3} \mathrm{~N},\left(\mathrm{CH}_{3}\right)_{2} \mathrm{O}$ and $\left(\mathrm{CH}_{3}\right)_{2} \mathrm{~S}$ form hydrogen and lithium bonds through the basic atoms and the geometry of the complexes is almost determined by the type and direction of the lone pairs involved in bonding. Therefore the PES of these complexes have been searched for stable structures from the various proposed geometries shown in Fig. 1.

(i) LiF complexes. Optimization and frequency calculations show that the $\left(\mathrm{CH}_{3}\right)_{3} \mathrm{~N} \cdots \mathrm{LiF}$ complex has a stable structure with $C_{3 \mathrm{v}}$ symmetry (I). Among the three structures considered for $\left(\mathrm{CH}_{3}\right)_{2} \mathrm{O}$ and $\left(\mathrm{CH}_{3}\right)_{2} \mathrm{~S}$ complexes (II, III, and IV) structure III of $\left(\mathrm{CH}_{3}\right)_{2} \mathrm{O} \cdots \mathrm{LiF}$ and structure IV of $\left(\mathrm{CH}_{3}\right)_{2} \mathrm{~S} \cdots \mathrm{LiF}$ are found to be the stable structures from frequency analyses. Thus each complex has only one stable structure and the structural diversity indicates the subtle differences in the nature of the interactions that stabilize them.

(ii) HF complexes. The structure of $\left(\mathrm{CH}_{3}\right)_{3} \mathrm{~N} \cdots \mathrm{HF}$ is found to be similar to that of the $\mathrm{LiF}$ complex. Structure I with $C_{3 \mathrm{v}}$ symmetry for the $\left(\mathrm{CH}_{3}\right)_{3} \mathrm{~N} \cdots \mathrm{HF}$ complex is confirmed to be the stable structure from frequency calculations. The potential energy surface of the $\left(\mathrm{CH}_{3}\right)_{2} \mathrm{O} \cdots \mathrm{HF}$ complex is different from that of LiF complex. Here, frequency analysis reveals that structure II with $C_{2 \mathrm{v}}$ symmetry is the stable structure. The $\left(\mathrm{CH}_{3}\right)_{2} \mathrm{~S} \cdots \mathrm{HF}$ complex is similar to that of $\left(\mathrm{CH}_{3}\right)_{2} \mathrm{~S} \cdots \mathrm{LiF}$ complex. Here again, IV is a minimum. As with the LiF complexes, only one stable structure is observed for each $\mathrm{HF}$ complex: I for $\left(\mathrm{CH}_{3}\right)_{3} \mathrm{~N} \cdots \mathrm{HF}$, II for $\left(\mathrm{CH}_{3}\right)_{2} \mathrm{O} \cdots \mathrm{HF}$ and IV for $\left(\mathrm{CH}_{3}\right)_{2} \mathrm{~S} \cdots \mathrm{HF}$.

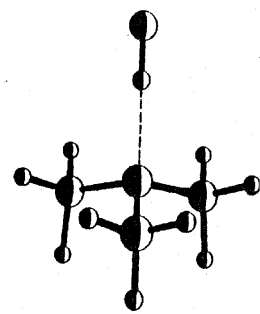

I
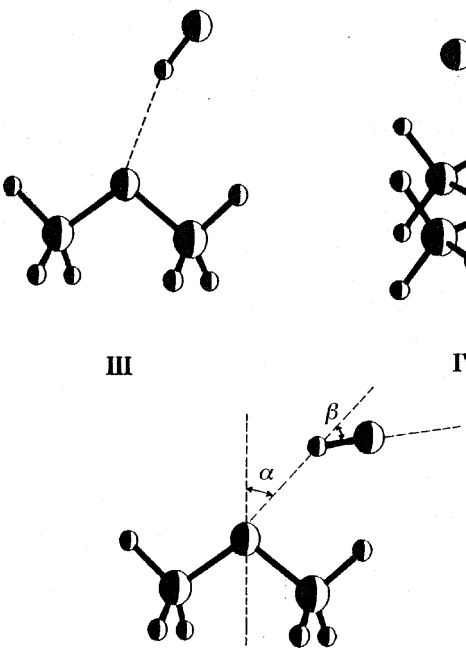

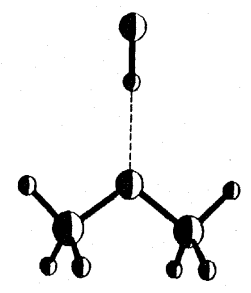

II

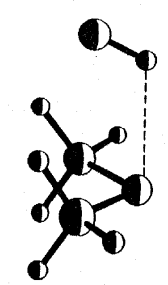

IV
Fig. 1 Different possible geometries for the complexes of $\mathrm{LiF}-\mathrm{HF}$ with amine (I), ether and sulfide (II-IV) and the model defining the angles $\alpha$ and $\beta$.

It appears from the above that $\mathrm{LiF}$ and $\mathrm{HF}$ complexes of amine and sulfide have quite similar geometries, while the geometries of $\mathrm{HF}$ and LiF complexes differ in ether. DFT and MP2 calculations have been undertaken only for the HF stable structures. The relative stability of the complexes, and the reason for the preferences of different forms for different complexes, are discussed in the following sections.

Latajka and co-workers ${ }^{23,24}$ have studied the complexes of amines with hydrogen halides and they proposed two geometries, neutral pair type and ion pair type for each complex based on their calculations. They showed that the $\left(\mathrm{CH}_{3}\right)_{3} \mathrm{~N}$ complex always exists in ion pair type. Normally when a hydrogen halide (HX) approaches the amine in the direction of the lone pair, at long ranges it forms a weak complex (neutral pair) and on moving further in the same direction the HX molecule forms the TS with the amine and then reacts to give the ion-pair. In the ion-pair the bond between the base atom and the proton is of covalent type. It is also possible with $\mathrm{LiF}$. As we are interested only in complex formation we have not scanned the PES for any TS or reaction product.

\section{Energetics}

The stable structures identified from the PES searches have been considered for further analysis. The relative stabilities of the complexes will be discussed from the energetics of the complexes. Complexation energies, calculated at HF, DFT, MP2 and MP4 levels are presented in Table 1. ZPE corrections to the DFT, MP2, and MP4 interaction energies could not be done as calculations of frequencies at these levels are computationally too demanding. For the same reason, MP4 single point energies are not reported for $\left(\mathrm{CH}_{3}\right)_{3} \mathrm{~N}$ complexes.

(i) LiF complexes. In all the three complexes, the $\mathrm{Li}$ atom interacts only with the basic atom of the donor. The Li-bond is found to be linear in the $\left(\mathrm{CH}_{3}\right)_{3} \mathrm{~N}$ complex and is angular in the other two complexes. The bent geometry of the Li-bond in $\left(\mathrm{CH}_{3}\right)_{2} \mathrm{O}$ and $\left(\mathrm{CH}_{3}\right)_{2} \mathrm{~S}$ complexes is due to the following 
Table 1 Complexation energies $\Delta E$, BSSE, counterpoise corrected complexation energies $\Delta E^{\mathrm{cp}}$, zero point energy correction (ZPEC), corrected complexation energies $\Delta E_{\mathrm{ZPEC}}^{\mathrm{cp}}\left(\mathrm{kcal} \mathrm{mol}^{-1}\right)$ computed at various levels for the Hartree-Fock stable structures of the complexes with $6-31++\mathrm{G}(\mathrm{d}, \mathrm{p})$ basis set

\begin{tabular}{|c|c|c|c|c|c|c|}
\hline complex & level & $\Delta E$ & BSSE & $\Delta E^{\mathrm{cp}}$ & ZPEC & $\Delta E_{\mathrm{ZPEC}}^{\mathrm{cp}}$ \\
\hline $\begin{array}{l}\left(\mathrm{CH}_{3}\right)_{3} \mathrm{~N} \cdots \mathrm{LiF} \\
\text { I }\end{array}$ & $\begin{array}{l}\text { HF } \\
\text { DFT } \\
\text { MP2 }\end{array}$ & $\begin{array}{l}21.62 \\
22.13 \\
23.48\end{array}$ & $\begin{array}{l}2.24 \\
2.65 \\
4.33\end{array}$ & $\begin{array}{l}19.38 \\
19.48 \\
19.15\end{array}$ & $\begin{array}{l}1.46 \\
-\end{array}$ & $\begin{array}{c}17.92 \\
- \\
-\end{array}$ \\
\hline $\begin{array}{l}\left(\mathrm{CH}_{3}\right)_{2} \mathrm{O} \cdots \mathrm{LiF} \\
\text { III }\end{array}$ & $\begin{array}{l}\text { HF } \\
\text { DFT } \\
\text { MP2 } \\
\text { MP4/MP2 }\end{array}$ & $\begin{array}{l}20.82 \\
20.88 \\
21.74 \\
21.99\end{array}$ & $\begin{array}{l}1.93 \\
2.05 \\
3.33 \\
3.67\end{array}$ & $\begin{array}{l}18.89 \\
18.83 \\
18.41 \\
18.32\end{array}$ & $\begin{array}{l}1.41 \\
- \\
-\end{array}$ & $\begin{array}{l}17.48 \\
- \\
-\end{array}$ \\
\hline $\begin{array}{l}\left(\mathrm{CH}_{3}\right)_{2} \mathrm{~S} \cdots \mathrm{LiF} \\
\text { IV }\end{array}$ & $\begin{array}{l}\text { HF } \\
\text { DFT } \\
\text { MP2 } \\
\text { MP4/MP2 }\end{array}$ & $\begin{array}{l}15.02 \\
16.57 \\
17.90 \\
18.22\end{array}$ & $\begin{array}{l}0.86 \\
1.30 \\
3.70 \\
4.06\end{array}$ & $\begin{array}{l}14.16 \\
15.27 \\
14.20 \\
14.16\end{array}$ & $\begin{array}{l}1.34 \\
- \\
-\end{array}$ & $\begin{array}{l}12.28 \\
- \\
-\end{array}$ \\
\hline $\begin{array}{l}\left(\mathrm{CH}_{3}\right)_{3} \mathrm{~N} \cdots \mathrm{HF} \\
\text { I }\end{array}$ & $\begin{array}{l}\text { HF } \\
\text { DFT } \\
\text { MP2 }\end{array}$ & $\begin{array}{l}11.95 \\
16.08 \\
16.84\end{array}$ & $\begin{array}{l}1.00 \\
1.05 \\
3.06\end{array}$ & $\begin{array}{l}10.95 \\
15.03 \\
13.78\end{array}$ & $\frac{2.71}{-}$ & $\begin{array}{l}8.24 \\
-\end{array}$ \\
\hline $\begin{array}{l}\left(\mathrm{CH}_{3}\right)_{2} \mathrm{O} \cdots \mathrm{HF} \\
\text { II }\end{array}$ & $\begin{array}{l}\text { HF } \\
\text { DFT } \\
\text { MP2 } \\
\text { MP4/MP2 }\end{array}$ & $\begin{array}{r}9.39 \\
11.02 \\
11.62 \\
11.54\end{array}$ & $\begin{array}{l}0.82 \\
0.78 \\
2.21 \\
2.45\end{array}$ & $\begin{array}{r}8.57 \\
10.24 \\
9.41 \\
9.09\end{array}$ & $\begin{array}{l}2.22 \\
- \\
-\end{array}$ & $\begin{array}{l}6.35 \\
- \\
-\end{array}$ \\
\hline $\begin{array}{l}\left(\mathrm{CH}_{3}\right)_{2} \mathrm{~S} \cdots \mathrm{HF} \\
\text { IV }\end{array}$ & $\begin{array}{l}\text { HF } \\
\text { DFT } \\
\text { MP2 } \\
\text { MP4/MP2 }\end{array}$ & $\begin{array}{l}5.62 \\
8.45 \\
7.90 \\
7.73\end{array}$ & $\begin{array}{l}0.28 \\
0.37 \\
1.54 \\
0.96\end{array}$ & $\begin{array}{l}5.34 \\
8.08 \\
6.36 \\
6.77\end{array}$ & $\begin{array}{l}1.74 \\
- \\
-\end{array}$ & $\begin{array}{l}3.60 \\
- \\
-\end{array}$ \\
\hline
\end{tabular}

reasons: (i) lithium can make bent bonds in view of the increased ion-dipole interactions, and (ii) the presence of a weak secondary attraction between the $\mathrm{F}$ atom of $\mathrm{LiF}$ and a methyl proton of the base. The binding energies calculated at all the levels show that the stability of the complexes decreases in the order $\left(\mathrm{CH}_{3}\right)_{3} \mathrm{~N}>\left(\mathrm{CH}_{3}\right)_{2} \mathrm{O} \gg\left(\mathrm{CH}_{3}\right)_{2} \mathrm{~S}$. BSSE and $\mathrm{ZPE}$ corrected binding energies of these complexes show that $\left(\mathrm{CH}_{3}\right)_{3} \mathrm{~N}$ and $\left(\mathrm{CH}_{3}\right)_{2} \mathrm{O}$ complexes lie close in stability while the $\left(\mathrm{CH}_{3}\right)_{2} \mathrm{~S}$ complex is far less stable. $\left(\mathrm{CH}_{3}\right)_{3} \mathrm{~N}$ forms a stronger complex compared to $\left(\mathrm{CH}_{3}\right)_{2} \mathrm{O}$ though the electronegativity increases in the row from the left to the right. Legon and Millen ${ }^{43}$ have calculated the nucleophilicities and electrophilicities of various bases and acids and their calculations show that the nucleophilicities decrease in the order $\mathrm{NH}_{3}(11.5)>\mathrm{H}_{2} \mathrm{O}(10.0)>\mathrm{H}_{2} \mathrm{~S}(4.8)$. This trend clearly shows that the bases with an $\mathrm{N}$ atom can form stronger complexes than those with $\mathrm{O}$ and $\mathrm{S}$ atoms; comparing oxygen and sulfur bases the latter forms much weaker complexes than the former. As mentioned earlier, there are no experimental or computational studies available for the complexes of $\mathrm{LiF}$ with $\left(\mathrm{CH}_{3}\right)_{3} \mathrm{~N},\left(\mathrm{CH}_{3}\right)_{2} \mathrm{O}$ and $\left(\mathrm{CH}_{3}\right)_{2} \mathrm{~S}$ for a straightforward comparison of our results. Abboud et al. ${ }^{33}$ have calculated the $\mathrm{Li}$ atom affinity of $\left(\mathrm{CH}_{3}\right)_{2} \mathrm{O}$ with a $4-31 \mathrm{G}$ basis as $50.9 \mathrm{kcal}$ mol $^{-1}$ and Blint ${ }^{34}$ has calculated the same with a D95V** basis set as $39.4 \mathrm{kcal} \mathrm{mol}^{-1}$ and compared it with the experimental value $41.5 \mathrm{kcal} \mathrm{mol}^{-1}{ }^{36}$ Smith et al. $^{35}$ reported the BSSE corrected binding energies for the $\left(\mathrm{CH}_{3}\right)_{2} \mathrm{O} \cdots \mathrm{Li}^{+}$ complex calculated at the MP2 level with a $\left(5 \mathrm{~s} 3 \mathrm{p} 2 \mathrm{~d} / \mathrm{D} 95+^{* *}\right)$ and $(5 \mathrm{~s} 3 \mathrm{p} 2 \mathrm{~d} / \mathrm{cc}-\mathrm{pVTZ}+\mathrm{sp})$ basis set as 39.12 and $38.41 \mathrm{kcal}$ $\mathrm{mol}^{-1}$, respectively. These values confirm that $\mathrm{LiF}$ forms a weaker complex with a base than with $\mathrm{Li}^{+}$as observed earlier. ${ }^{16}$

Comparison of the binding energies of the $\mathrm{LiF}$ complexes of $\mathrm{n}$-donors with our earlier results $^{16}$ on $\pi \rightarrow \sigma^{*}$ and $(\mathrm{n}+\pi) \rightarrow \sigma^{*}$ complexes shows the following trend. $\mathrm{n} \rightarrow \sigma^{*}$ complexes are stronger than $\pi \rightarrow \sigma^{*}$ complexes but they are weaker than $(\mathrm{n}+\pi) \rightarrow \sigma^{*}$ complexes. It should be noted here that in the stable structure of $(n+\pi)$ donor $\mathrm{H}_{2} \mathrm{CO}$ and $\mathrm{H}_{2} \mathrm{CS}$ complexes, the secondary hydrogen bonding interactions are stronger than those found in $\left(\mathrm{CH}_{3}\right)_{2} \mathrm{O}$ and $\left(\mathrm{CH}_{3}\right)_{2} \mathrm{~S}$ complexes. (ii) $\mathrm{HF}$ complexes. $\mathrm{HF}$ forms a $C_{3 \mathrm{v}}$ complex with $\left(\mathrm{CH}_{3}\right)_{3} \mathrm{~N}$ similar to $\mathrm{LiF}$, whereas the structures of $\left(\mathrm{CH}_{3}\right)_{2} \mathrm{O} \cdots \mathrm{HF}\left(\mathrm{C}_{2 \mathrm{v}}\right)$ and $\left(\mathrm{CH}_{3}\right)_{2} \mathrm{~S} \cdots \mathrm{HF}\left(\mathrm{C}_{\mathrm{s}}\right)$ are slightly different from those of the $\mathrm{LiF}$ complexes. The stability order of the $\mathrm{HF}$ complexes decreases in the order $\left(\mathrm{CH}_{3}\right)_{3} \mathrm{~N}>\left(\mathrm{CH}_{3}\right)_{2} \mathrm{O}>\left(\mathrm{CH}_{3}\right)_{2} \mathrm{~S}$. The difference in the binding energies of the HF complexes of $\left(\mathrm{CH}_{3}\right)_{3} \mathrm{~N}$ and $\left(\mathrm{CH}_{3}\right)_{2} \mathrm{O}$ is larger than that of $\mathrm{LiF}$ complexes. This trend is again in accordance with the relative nucleophilicities of $\mathrm{N}, \mathrm{O}$, and $\mathrm{S}$ bases.

It is appropriate to compare our results with earlier reported values. Carnovale et al. ${ }^{25}$ reported the binding energies calculated with STO-3G* and 4-31G basis sets for the $\left(\mathrm{CH}_{3}\right)_{2} \mathrm{O} \cdots \mathrm{HF}$ complex as 14.34 and $13.62 \mathrm{kcal} \mathrm{mol}^{-1}$, and for the $\left(\mathrm{CH}_{3}\right)_{2} \mathrm{~S} \cdots \mathrm{HF}$ complex as 8.60 and $7.65 \mathrm{kcal} \mathrm{mol}^{-1}$, respectively. The hydrogen bond energy observed in IR spectroscopic study is available only for the $\left(\mathrm{CH}_{3}\right)_{2} \mathrm{O} \cdots \mathrm{HF}$ complex, and is $10.28 \mathrm{kcal} \mathrm{mol}^{-1} .{ }^{44}$ This value agrees well with our calculated binding energy at the DFT level. These complexes $\left(n \rightarrow \sigma^{*}\right)$ are found to be stronger than $\pi \rightarrow \sigma^{*}$ and $(\mathrm{n}+\pi) \rightarrow \sigma^{*}$ complexes. $^{16}$

The comparison of binding energies of $\mathrm{LiF}$ and $\mathrm{HF}$ complexes predict that $\mathrm{LiF}$ forms stronger complexes with lonepair donors than HF. The stability order observed in the complexes of $\mathrm{LiF}$ and $\mathrm{HF}$ with different electron donors are found to be the same and this parallels the trend observed in the nucleophilicities of the bases. The effect of electron correlation on the binding energy is considerable in HF complexes and almost negligible in LiF complexes.

\section{Structure and bonding}

The formation of hydrogen and lithium bonds induces electronic flow from the electron donor to the acceptor; almost all the atoms of the interacting molecules are involved in this. This results in changes in the geometrical parameters of the interacting molecules besides forming an intermolecular bond. Therefore structural analyses of the complexes give useful clues as to the nature of interactions that stabilize the complex. The geometric data of the monomers and complexes that are vital for the structural analyses are compiled in Table 
Table 2 Selected MP2 structural parameters for the monomers and complexes optimized with $6-31++G(d, p)$ basis set

\begin{tabular}{|c|c|c|c|c|c|c|c|c|c|}
\hline \multirow[b]{2}{*}{ parameter $^{a}$} & \multicolumn{3}{|c|}{ monomers $^{b}$} & \multicolumn{3}{|c|}{ LiF complexes } & \multicolumn{3}{|c|}{ HF complexes } \\
\hline & $\left(\mathrm{CH}_{3}\right)_{3} \mathrm{~N}$ & $\left(\mathrm{CH}_{3}\right)_{2} \mathrm{O}$ & $\left(\mathrm{CH}_{3}\right)_{2} \mathrm{~S}$ & I & III & IV & I & II & IV \\
\hline$R_{\mathrm{Z}-\mathrm{F}}$ & - & - & - & 1.627 & 1.634 & 1.636 & 0.989 & 0.949 & 0.945 \\
\hline$R_{\mathrm{Y}-\mathrm{Z}}$ & - & - & - & 2.076 & 1.911 & 2.444 & 1.559 & 1.639 & 2.183 \\
\hline$R_{\mathrm{C}-\mathrm{Y}}$ & 1.455 & 1.419 & 1.805 & 1.471 & $1.429,1.443$ & 1.815 & 1.466 & 1.427 & 1.806 \\
\hline$R_{\mathrm{C}-\mathrm{H}}$ & $1.103,1.089$ & $1.086,1.095$ & $1.788,1.089$ & $1.098,1.089$ & $1.087,1.091$ & $1.088,1.089$ & $1.097,1.089$ & $1.086,1.092$ & $1.088,1.089$ \\
\hline$R_{\mathrm{F}-\mathrm{H}}$ & - & - & - & 4.361 & 2.529 & 2.479 & 3.353 & 3.362 & 3.516 \\
\hline$\theta_{\mathrm{Y}-\mathrm{Z}-\mathrm{F}}$ & - & - & - & 180.0 & 128.6 & 110.9 & 180.0 & 180.0 & 169.9 \\
\hline$\theta_{\mathrm{C}-\mathrm{Y}-\mathrm{Z}}$ & - & - & - & 109.3 & $141.3,106.5$ & 88.7 & 108.2 & 123.6 & 99.1 \\
\hline$\theta_{\mathrm{C}-\mathrm{Y}-\mathrm{C}}$ & 110.6 & 111.2 & 98.2 & 109.6 & 112.1 & 97.9 & 110.7 & 112.9 & 98.9 \\
\hline$\theta_{\mathrm{H}-\mathrm{C}-\mathrm{Y}}$ & $112.4,109.5$ & $106.9,111.0$ & $107.7,112.2$ & $111.3,109.6$ & $107.3,110.1$ & $107.9,107.8$ & $111.4,109.2$ & $106.8,110.3$ & $107.7,110.9$ \\
\hline$\theta_{\mathrm{H}-\mathrm{C}-\mathrm{H}}$ & $108.4,108.6$ & $109.5,108.9$ & $108.6,109.6$ & $108.8,108.9$ & $109.8,109.6$ & $110.2,110.8$ & $109.1,108.7$ & $109.9,109.6$ & $108.9,109.9$ \\
\hline$\alpha$ & - & - & - & 0.0 & 17.5 & 91.9 & 0.0 & 0.0 & 75.9 \\
\hline$\beta$ & - & - & - & 0.0 & 51.4 & 69.1 & 0.0 & 0.0 & 10.1 \\
\hline
\end{tabular}

I amine complex, II and III ether complexes and IV sulfide complex. ${ }^{a}$ Bond lengths in $\AA$ and bond angles in degrees. For $\alpha$ and $\beta$ see Fig. 1 . $\mathrm{Z}=\mathrm{Li}, \mathrm{H}$ in $\mathrm{LiF}$ and $\mathrm{HF}$ respectively, $\mathrm{Y}=\mathrm{N}, \mathrm{O}, \mathrm{S}$ in amine, ether, and sulfide, respectively. ${ }^{b} \mathrm{MP} 2 \mathrm{LiF}$ and $\mathrm{HF}$ bond lengths are 1.609 and $0.927 \AA$.

2. The overall geometry of these complexes can be best described using two parameters $\alpha$ and $\beta$, which are indicated in Fig. 1. While $\alpha$ shows the extent of the deviation of the position of the $\mathrm{Z}$ atom from the major axis (the $C_{3}$ axis in amine and the $C_{2}$ axis in ether and sulfide), $\beta$ is a measure of the deviation from collinearity of the intermolecular bond axis and the $\mathrm{Z}-\mathrm{F}$ molecular axis. The torsion angle $\mathrm{CYCZ}$ is $180^{\circ}$ for the ether complex and $90^{\circ}$ for the sulfide complex. $\alpha$ and $\beta$ can be derived from the computed structural parameters shown in Table 2.

(i) LiF complexes. The amine complex has a linear lithium bond $\alpha=0^{\circ}, \beta=0^{\circ}$, while the ether and sulfide complexes have bent lithium bonds with $\alpha$ and $\beta$ respectively $16.4^{\circ}, 49.6^{\circ}$ and $92.3^{\circ}, 66.4^{\circ}$. The $\mathrm{C}-\mathrm{N} \cdots \mathrm{Li}$ angle is characteristic of the tetrahedral geometry of the complex. Two different $\mathrm{C}-\mathrm{O} \cdots \mathrm{Li}$ bond angles observed here show that the $\mathrm{Li}-\mathrm{F}$ axis deviates from the $C_{2}$ axis of ether but it is confined within the $\mathrm{C}-\mathrm{O}-\mathrm{C}$ plane. Such a deviation may arise due to the electrostatic interaction between the fluorine atom and methyl protons. Sulfur prefers a perpendicular lithium bond with the $\mathrm{C}-\mathrm{S} \cdots \mathrm{Li}$ angle nearly $90^{\circ}$. Here $\mathrm{LiF}$ is confined to the $\mathrm{C}-\mathrm{S}-\mathrm{C}$ angle bisecting plane. The $\mathrm{Y} \cdots \mathrm{Li}-\mathrm{F}$ angles differ considerably in the complexes. $\mathrm{F} \cdot \mathrm{H}$ distances listed in Table 2 reveal that the ether and sulfide complexes have secondary hydrogen bonding interaction involving the fluorine atom and the methyl protons, while the amine complex doesn't. DFT and MP2 computations show a stronger hydrogen bond between these atoms as both methods include correlation energy that is a significant component of the hydrogen bond energy. The secondary hydrogen bond is a bifurcated hydrogen bond in sulfide and is the simple hydrogen bond in ether.

On complexation, the $\mathrm{Li}-\mathrm{F}$ bond length increases as expected and the increase in this $\mathrm{Li}-\mathrm{F}$ distance is in the order $\left(\mathrm{CH}_{3}\right)_{3} \mathrm{~N}<\left(\mathrm{CH}_{3}\right)_{2} \mathrm{O}<\left(\mathrm{CH}_{3}\right)_{2} \mathrm{~S}$. It should be noted here that the stability of the complexes is in the reverse order. This is due to the presence of the weak secondary hydrogen bonding interaction in $\left(\mathrm{CH}_{3}\right)_{2} \mathrm{O}$ and $\left(\mathrm{CH}_{3}\right)_{2} \mathrm{~S}$ complexes; it is absent in the $\left(\mathrm{CH}_{3}\right)_{3} \mathrm{~N}$ complex. The $\mathrm{Li}-\mathrm{F}$ bond stretches further to form the hydrogen bond in $\left(\mathrm{CH}_{3}\right)_{2} \mathrm{O}$ and $\left(\mathrm{CH}_{3}\right)_{2} \mathrm{~S}$ complexes.

(ii) HF complexes. HF complexes are stabilized only by the hydrogen bonding interaction $\mathrm{Y} \cdots \mathrm{H}$. The hydrogen bonds are perfectly linear in amine and ether complexes and slightly bent in the sulfide complex. The $\mathrm{C}-\mathrm{Y} \cdots \mathrm{H}$ angle in $\left(\mathrm{CH}_{3}\right)_{2} \mathrm{~S} \cdots \mathrm{HF}\left(\mathrm{ca} .100^{\circ}\right)$ shows that sulfur prefers a perpendicular hydrogen bond in line with earlier observations. ${ }^{45}$ It is interesting to observe that the lithium bonds to sulfur are more perpendicular than hydrogen bonds. On complexation, $\mathrm{H}-\mathrm{F}$ and $\mathrm{C}-\mathrm{Y}$ bonds are weakened and the increase in bond lengths is in the order $\left(\mathrm{CH}_{3}\right)_{3} \mathrm{~N}>\left(\mathrm{CH}_{3}\right)_{2} \mathrm{O}>\left(\mathrm{CH}_{3}\right)_{2} \mathrm{~S}$.
This trend parallels the trend observed in the stability of the complexes which again proves that these complexes are stabilized only by the primary hydrogen bonding interaction and charge transfer interaction is the main force. The $\mathrm{Y} \cdots \mathrm{H}$ distances predict the formation of a hydrogen bond between the monomers and these bond lengths are found to be shorter than their corresponding $\mathrm{Y} \cdots \mathrm{Li}$ bonds though the hydrogen bonds are weaker than the lithium bonds. The greater intermolecular distance in the lithium bonds is attributed to the fact that $\mathrm{Li}$ almost exists as $\mathrm{Li}^{+}$in lithium halides and this $\mathrm{Li}^{+}$with an inner closed shell cannot penetrate deeply into the charge cloud of the electron donor molecule, whereas a hydrogen atom can do so because of the smaller size of its charge cloud.

\section{Analysis of interactions}

NBO analyses have been performed on the $6-31++G(d, p)$ wavefunction of the stable forms of the complexes at all levels. The occupancies of the monomer orbitals that are involved in the charge transfer interaction the charge transfer $q_{\mathrm{CT}}$ from the base to $\mathrm{LiF} / \mathrm{HF}$, occupancies of the frontier molecular orbitals and the second order perturbation energy lowering $\left(\Delta E^{2}\right)$ due to the interaction of the donor and acceptor orbitals are summarized in Table 3.

(i) $\mathrm{LiF}$ complexes. The structures of the complexes have suggested that the $\left(\mathrm{CH}_{3}\right)_{3} \mathrm{~N}$ complex is stabilized only by lithium bonding, whereas $\left(\mathrm{CH}_{3}\right)_{2} \mathrm{O}$ and $\left(\mathrm{CH}_{3}\right)_{2} \mathrm{~S}$ complexes derive stability mainly from lithium bonding and to a smaller degree from weak secondary hydrogen bonding interactions. The $q_{\mathrm{CT}}$ values listed in Table 3 show that the charge transfer increases in the order $\left(\mathrm{CH}_{3}\right)_{2} \mathrm{~S}>\left(\mathrm{CH}_{3}\right)_{2} \mathrm{O}>\left(\mathrm{CH}_{3}\right)_{3} \mathrm{~N}$; a larger $q_{\mathrm{CT}}$ means a larger charge transfer stabilization. This trend in $q_{\mathrm{CT}}$ does not concur with the stability order found in these complexes. For instance the sulfide complex that has the highest charge transfer is found to be the least stable among the three. Such differing trends in $q_{\mathrm{CT}}$ and binding energy only indicate the dominance of the electrostatic interaction to the overall stability. The charge transfer interaction contributes only slightly to stability.

The $\Delta E^{2}$ value for the $\left(\mathrm{CH}_{3}\right)_{3} \mathrm{~N}$ complex clearly shows that the nitrogen lone pair $n(N)$ and the antibonding orbital of $\mathrm{Li}-\mathrm{F}$ are involved in the charge transfer process. The occupancy of $\sigma_{\mathrm{Li}-\mathrm{F}}^{*}$ increases and that of $\mathrm{n}(\mathrm{N})$ also increases slightly instead of an expected decrease. This is due to the increased charge flow from the methyl protons towards the nitrogen atom during complexation, indicated by the greater decrease in the occupancy of the $\sigma_{\mathrm{C}-\mathrm{H}}^{*}$ orbital in the $\left(\mathrm{CH}_{3}\right)_{3} \mathrm{~N}$ complex compared to the other two complexes. In the $\left(\mathrm{CH}_{3}\right)_{2} \mathrm{O}$ complex, the occupancy of the $n_{\sigma}$ orbital of oxygen decreases and that of $n_{\pi}$ increases whereas the occupancies of both $n_{\sigma}$ 
Table 3 Natural bond orbital analysis for the monomers and LiF and HF complexes calculated with 6-31+ $+\mathrm{G}(\mathrm{d}, \mathrm{p})$ basis set

\begin{tabular}{|c|c|c|c|c|c|c|}
\hline \multirow[b]{3}{*}{ parameters $^{a}$} & \multicolumn{3}{|c|}{ DFT } & \multicolumn{3}{|c|}{ MP2 } \\
\hline & \multicolumn{6}{|c|}{ monomer $^{b}$} \\
\hline & $\left(\mathrm{CH}_{3}\right)_{3} \mathrm{~N}$ & $\left(\mathrm{CH}_{3}\right)_{2} \mathrm{O}$ & $\left(\mathrm{CH}_{3}\right)_{2} \mathrm{~S}$ & $\left(\mathrm{CH}_{3}\right)_{3} \mathrm{~N}$ & $\left(\mathrm{CH}_{3}\right)_{2} \mathrm{O}$ & $\left(\mathrm{CH}_{3}\right)_{2} \mathrm{~S}$ \\
\hline$n_{\sigma}(\mathrm{Y})$ & 1.878 & 1.969 & 1.989 & 1.915 & 1.978 & 1.991 \\
\hline$n_{\pi}(\mathrm{Y})$ & - & 1.923 & 1.944 & - & 1.947 & 1.952 \\
\hline \multirow[t]{3}{*}{$\sigma^{*}(\mathrm{C}-\mathrm{H})$} & 0.029 & 0.009 & 0.015 & 0.020 & 0.007 & 0.013 \\
\hline & \multicolumn{6}{|c|}{ LiF complexes } \\
\hline & I & III & IV & $\mathbf{I}$ & III & IV \\
\hline $\begin{array}{l}q_{\mathrm{CT}} \\
\text { occupancy }\end{array}$ & 0.032 & 0.014 & 0.036 & 0.030 & 0.015 & 0.038 \\
\hline$n_{\sigma}(\mathrm{Y})$ & 1.889 & 1.959 & 1.988 & 1.914 & 1.967 & 1.989 \\
\hline$n_{\pi}(\mathrm{Y})$ & - & 1.939 & 1.918 & - & 1.958 & 1.927 \\
\hline$\sigma^{\pi *}(\mathrm{Li}-\mathrm{F})$ & 0.055 & 0.036 & 0.060 & 0.048 & 0.033 & 0.056 \\
\hline$n_{\pi}(\mathrm{F})$ & 1.993 & 1.988 & 1.986 & 1.996 & 1.994 & 1.992 \\
\hline$\sigma^{*}(\mathrm{C}-\mathrm{H})$ & 0.020 & 0.010 & 0.014 & 0.015 & 0.007 & 0.012 \\
\hline \multirow{6}{*}{$\begin{array}{l}\Delta E^{2}\left(\mathrm{kcal} \mathrm{mol}^{-1}\right) \\
n_{\sigma}(\mathrm{Y}), \sigma^{*}(\mathrm{Li}-\mathrm{F}) \\
n_{\pi}(\mathrm{Y}), \sigma^{*}(\mathrm{Li}-\mathrm{F}) \\
n_{\pi}(\mathrm{F}), \sigma^{*}(\mathrm{C}-\mathrm{H})\end{array}$} & & & & & & \\
\hline & 10.13 & 9.61 & 1.40 & 13.51 & 12.04 & 1.89 \\
\hline & - & - & 12.75 & - & - & 17.64 \\
\hline & - & 1.17 & 0.84 & - & 1.18 & 1.00 \\
\hline & \multicolumn{6}{|c|}{ HF complexes } \\
\hline & I & II & IV & I & II & IV \\
\hline $\begin{array}{l}q_{\mathrm{CT}} \\
\text { occupancy }\end{array}$ & 0.105 & 0.049 & 0.081 & 0.089 & 0.037 & 0.058 \\
\hline$n_{\sigma}(\mathrm{Y})$ & 1.822 & 1.925 & 1.986 & 1.858 & 1.945 & 1.987 \\
\hline$n_{\pi}(\mathrm{Y})$ & - & 1.937 & 1.881 & - & 1.956 & 1.909 \\
\hline$\sigma^{*}(\mathrm{H}-\mathrm{F})$ & 0.106 & 0.052 & 0.075 & 0.087 & 0.037 & 0.051 \\
\hline \multicolumn{7}{|l|}{$\Delta E^{2}\left(\mathrm{kcal} \mathrm{mol}^{-1}\right)$} \\
\hline$n_{\sigma}(\mathrm{Y}), \sigma^{*}(\mathrm{H}-\mathrm{F})$ & 44.19 & 25.03 & 1.25 & 57.78 & 28.47 & 1.52 \\
\hline$n_{\pi}(\mathrm{Y}), \sigma^{*}(\mathrm{H}-\mathrm{F})$ & - & - & 23.77 & - & - & 26.13 \\
\hline
\end{tabular}

I amine complex, II, III ether complexes and IV sulfide complex. ${ }^{a} \mathrm{Y}=\mathrm{N}, \mathrm{O}$ and $\mathrm{S}$ in amine, ether and sulfide, respectively. ${ }^{b} \mathrm{DFT}(\mathrm{MP} 2)$ occupancies $n_{\pi}(\mathrm{F})$ and $\sigma^{*}(\mathrm{Li}-\mathrm{F})$ in $\mathrm{Li}-\mathrm{F}$ are $1.991(1.994)$ and $0.009(0.009)$ respectively. $\sigma^{*}(\mathrm{H}-\mathrm{F})$ in $\mathrm{HF}$ is $0.000(0.000)$. $q_{\mathrm{CT}}$ and occupancies in number of electrons.

and $\mathrm{n}_{\pi}$ of sulfur decrease in the $\left(\mathrm{CH}_{3}\right)_{2} \mathrm{~S}$ complex on complexation. The decrease in $n_{\pi}$ of sulfur is more than in $n_{\sigma}$ and these trends reveal that oxygen donates its $n_{\sigma}$ electrons while sulfur donates its $\mathrm{n}_{\pi}$ electrons to the $\sigma_{\mathrm{Li}-\mathrm{F}}^{*}$ orbital. The above fact is further confirmed by the $\Delta E^{2}$ values for the $\mathrm{n}_{\sigma}(\mathrm{Y})-\sigma_{\mathrm{Li}-\mathrm{F}}^{*}$ and $\mathrm{n}_{\pi}(\mathrm{Y})-\sigma_{\mathrm{Li}-\mathrm{F}}^{*}$ interactions. The occupancies of the $\mathrm{Li}-\mathrm{F}$ antibonding orbitals increase in the order $\left(\mathrm{CH}_{3}\right)_{2} \mathrm{O}<\left(\mathrm{CH}_{3}\right)_{3} \mathrm{~N}<$ $\left(\mathrm{CH}_{3}\right)_{2} \mathrm{~S}$, a trend parallel to the amount of charge transfer in the complexes.

NBO analyses of the secondary hydrogen bonding interaction in $\left(\mathrm{CH}_{3}\right)_{2} \mathrm{O}$ and $\left(\mathrm{CH}_{3}\right)_{2} \mathrm{~S}$ complexes reveal the following. The $\Delta E^{2}$ values show that the $\mathrm{n}_{\pi}$ of the fluorine atom and the $\mathrm{C}-\mathrm{H}$ antibond orbitals are involved in the charge transfer process. The occupancy of the $n_{\pi}(\mathrm{F})$ orbital in the $\left(\mathrm{CH}_{3}\right)_{2} \mathrm{O}$ complex remains almost unchanged at the HF and MP2 levels and decreases at the DFT level. This is a consequence of the relatively strong hydrogen bonding predicted at the DFT level. In the $\left(\mathrm{CH}_{3}\right)_{2} \mathrm{~S}$ complex, a decrease in the occupancy of the $n_{\pi}(F)$ is observed at all levels, which confirms that the hydrogen bond is stronger in this complex than in the $\left(\mathrm{CH}_{3}\right)_{2} \mathrm{O}$ complex. In both complexes, $\sigma_{\mathrm{C}-\mathrm{H}}^{*}$ occupancies decrease instead of an expected increase. This decrease is found to be less compared to the $\left(\mathrm{CH}_{3}\right)_{3} \mathrm{~N}$ complex and is due to the flow of the $\mathrm{C}-\mathrm{H}$ antibond electrons towards the base atom during complexation. The $\Delta E^{2}$ values calculated at the $\mathrm{HF}$ level are greater for the $\left(\mathrm{CH}_{3}\right)_{2} \mathrm{~S}$ complex, whereas at the DFT and MP2 levels they are greater for the $\left(\mathrm{CH}_{3}\right)_{2} \mathrm{O}$ complex. It is to be noted here that, in the $\left(\mathrm{CH}_{3}\right)_{2} \mathrm{O}$ complex the interaction of $n_{\pi}(F)$ is with one $\mathrm{C}-\mathrm{H}$ bond while it is with two $\mathrm{C}-\mathrm{H}$ bonds in the $\left(\mathrm{CH}_{3}\right)_{2} \mathrm{~S}$ complex. This again confirms that the secondary hydrogen bonding interaction is stronger in the $\left(\mathrm{CH}_{3}\right)_{2} \mathrm{~S}$ complex than in the $\left(\mathrm{CH}_{3}\right)_{2} \mathrm{O}$ complex. In both cases, the hydrogen bond is perpendicular and therefore it selects the $n_{\pi}(F)$ orbital for interaction rather than the $n_{\sigma}(F)$ orbital.

(ii) HF complexes. NBO analysis of the HF complexes again confirms that these complexes are stabilized only by the primary hydrogen bonding interaction. The $q_{\mathrm{CT}}$ values decrease in the order $\left(\mathrm{CH}_{3}\right)_{3} \mathrm{~N}>\left(\mathrm{CH}_{3}\right)_{2} \mathrm{~S}>\left(\mathrm{CH}_{3}\right)_{2} \mathrm{O}$. The $\left(\mathrm{CH}_{3}\right)_{3} \mathrm{~N} \cdots \mathrm{HF}$ complex is the strongest among the three and the charge transfer from the base to HF is also larger in this complex. This reveals that the charge transfer interaction has a significant role in hydrogen bonds. However, the charge transfer is more in $\left(\mathrm{CH}_{3}\right)_{2} \mathrm{~S} \cdot \mathrm{HF}$ compared to $\left(\mathrm{CH}_{3}\right)_{2} \mathrm{O} \cdots \mathrm{HF}$ though the former is weaker than the latter. The hydrogen bonds with a sulfur base are perpendicular and are dominated by a charge-multipole interaction whereas with an oxygen base the bond is linear and is dominated by a charge-charge interaction. ${ }^{45}$ Similar to $\mathrm{LiF}$ complexes, $\mathrm{HF}$ complexes show the following characteristics. In the $\left(\mathrm{CH}_{3}\right)_{3} \mathrm{~N}$ complex the lone pair of nitrogen $\mathrm{n}(\mathrm{N})$ donates electrons to the $\sigma_{\mathrm{C}-\mathrm{H}}^{*}$ orbital. In the $\left(\mathrm{CH}_{3}\right)_{2} \mathrm{O}$ complex, $\mathrm{n}_{\sigma}(\mathrm{O})$ is involved in donation whereas it is $n_{\pi}(\mathrm{S})$ in the $\left(\mathrm{CH}_{3}\right)_{2} \mathrm{~S}$ complex. The occupancies of the corresponding donor orbitals decrease and that of $\sigma_{\mathrm{H}-\mathrm{F}}^{*}$ increases upon complexation. The $\Delta E^{2}$ values decrease in the order $\left(\mathrm{CH}_{3}\right)_{3} \mathrm{~N}>\left(\mathrm{CH}_{3}\right)_{2} \mathrm{O}>\left(\mathrm{CH}_{3}\right)_{2} \mathrm{~S}$ and this parallels the trend observed in the stability of the complexes. This again would indicate that the charge transfer interaction is far more important in hydrogen bonds than in lithium bonds. Usually when a charge transfer interaction makes a dominant contribution to stability, the change transfer energy $\Delta E_{\mathrm{CT}}$ (dominated by $\Delta E^{2}$ ) is greater than the complexation energy, $\Delta E .^{46}$ Roughly a transfer of $0.01 e$ charge would correspond to $6 \mathrm{kcal} \mathrm{mol}^{-1}$ of 
$\Delta E_{\mathrm{CT}}$. This high $\Delta E_{\mathrm{CT}}$ is partially offset by the exchange repulsion at closer distance and results in a lower $\Delta E$. When the electrostatic contribution is high, $\Delta E>\Delta E_{\mathrm{CT}} \cdot{ }^{46}$ Trends observed in $\Delta E^{\mathrm{CP}}$ and $\Delta E^{2}$ in the $\mathrm{LiF}$ and $\mathrm{HF}$ complexes here (Table 3) made it clear further that charge transfer plays a more significant role in hydrogen bonds than in lithium bonds.

\section{Conclusions}

$\mathrm{LiF}$ and $\mathrm{HF}$ form $\mathrm{n} \rightarrow \sigma^{*}$ complexes with trimethylamine, dimethyl ether and dimethyl sulfide and each complex is found to have only one stable conformer. While LiF and HF complexes of the amine and sulfide have quite similar geometries, those of the ether differ considerably. These complexes are stronger than the analogous $\pi \rightarrow \sigma^{*}$ complexes. ${ }^{16}$ The amine and ether form stronger complexes than the sulfide as predicted by the order of nucleophilicities of the bases. An experimental hydrogen bond energy of $10.28 \mathrm{kcal} \mathrm{mol}^{-1}$ for the $\left(\mathrm{CH}_{3}\right)_{2} \mathrm{O} \cdots \mathrm{HF}$ complex observed from IR studies agrees excellently with the DFT binding energy. LiF forms stronger complexes than HF. Electron correlation has a considerable effect on the binding energies of HF complexes compared to $\mathrm{LiF}$ complexes. The main stabilizing force in the $\mathrm{LiF}$ and $\mathrm{HF}$ complexes is the lithium or hydrogen bonding interaction, but the LiF complexes of the ether and sulfide also have stabilization from secondary hydrogen bonding interactions. Generally, the amine and ether prefer linear lithium/hydrogen bonds, while sulfur prefers perpendicular lithium/hydrogen bonds in line with the previous studies. ${ }^{45}$ Slight deviation from linearity in the $\mathrm{LiF} \cdots \mathrm{O}\left(\mathrm{CH}_{3}\right)_{2}$ complex arises from an electrostatic interaction of fluorine with methyl protons. NBO analysis reveals that the amine and ether donate their $n_{\sigma}$ lone pair and sulfide donates its $\mathrm{n}_{\pi}$ lone pair. In the secondary hydrogen bonding interaction, found in $\left(\mathrm{CH}_{3}\right)_{2} \mathrm{O} \cdots \mathrm{LiF}$ and $\left(\mathrm{CH}_{3}\right)_{2} \mathrm{~S} \cdots \mathrm{LiF}$ complexes, the $\mathrm{n}_{\pi}(\mathrm{F})$ and $\sigma^{*}(\mathrm{C}-\mathrm{H})$ orbitals are involved. Charge transfer interactions contribute almost equally to $\mathrm{Li}$ and $\mathrm{H}$-bonds but the electrostatic interaction is greater in the Li-bond.

We thank the UGC, India for a senior research fellowship to one of us (SSCA), the CSIR, India for the financial support through a major research grant (01(1378)/95/EMR-II) and the referees for their critical comments.

\section{References}

1 C. Pimental and A. L. McClellan, The Hydrogen Bond, Freeman, San Fransisco, 1960.

2 A. C. Legon and D. J. Millen, Acc. Chem. Res., 1987, $20,39$.

3 L. A. Curtiss and M. Blander, Chem. Rev., 1988, 88, 827.

4 G. R. Desiraju, Acc. Chem. Res., 1991, 24, 290.

5 G. A. Jeffrey and W. Saenger, Hydrogen Bonding in Biological Structures, Springer-Verlag, Berlin, New York, Heidelberg, 1991.

6 S. Scheiner, Acc. Chem. Res., 1994, 27, 402.

7 G. A. Jeffrey, An Introduction to Hydrogen Bonding, Oxford University Press, New York, 1997.

8 A. C. Legon and D. J. Millen, Faraday Discuss. Chem. Soc., 1982, 73,71 .

9 A. C. Legon and D. J. Millen, Chem. Soc. Rev., 1987, 16, 467.

10 A. D. Buckingham and P. W. Fowler, Can. J. Chem., 1985, 63, 2014.
11 R. S. Mulliken, J. Phys. Chem., 1952, 56, 801.

12 A. E. Reed, F. Weinhold, L. A. Curtiss and D. J. Pochatko, J. Chem. Phys., 1986, 84, 5687.

13 A. E. Reed, L. A. Curtiss and F. Weinhold, Chem. Rev., 1988, 88, 899.

14 A. B. Sannigrahi, T. Kar and B. Guha Niyogi, Proc. Indian Acad. Sci. (Chem. Sci.), 1986, 96, 253.

15 A. B. Sannigrahi, T. Kar, B. Guha Niyogi, P. Hobza and P. von Ragué Schleyer, Chem. Rev., 1990, 90, 1061.

16 S. Salai Cheettu Ammal, P. Venuvanalingam and Sourav Pal, $J$. Chem. Phys., 1997, 107, 4329; S. Salai Cheettu Ammal and P. Venuvanalingam, J. Am. Chem. Soc., submitted; S. Salai Cheettu Ammal and P. Venuvanalingam, J. Chem. Phys., submitted.

17 A. C. Legon and C. A. Rego, Chem. Phys. Lett., 1989, 154, 468.

18 A. C. Legon and C. A. Rego, Chem. Phys. Lett., 1989, 157, 243.

19 A. C. Legon and C. A. Rego, Chem. Phys. Lett., 1989, 162, 369.

20 P. W. Fowler, A. C. Legon, C. A. Rego and P. Tole, Chem. Phys., 1989, 134, 297.

21 A. C. Legon, A. L. Wallwork and C. A. Rego, J. Chem. Phys., 1990, 92, 6397.

22 A. C. Legon, Chem. Soc. Rev., 1993, 22, 153.

23 Z. Latajka, S. Sakai, K. Morokuma and H. Ratajczak, Chem. Phys. Lett., 1984, 110, 464.

24 Z. Latajka, S. Scheiner and H. Ratajczak, Chem. Phys., 1992, 166, 85.

25 F. Carnovale, M. K. Livett and J. B. Peel, J. Am. Chem. Soc., $1982,104,5334$.

26 Z. Latajka and S. Scheiner, J. Chem. Phys., 1984, 81, 4014.

27 Z. Latajka, H. Ratajczak, K. Morokuma and W. J. OrvilleThomas, J. Mol. Struct.: THEOCHEM, 1986, 200, 117.

28 J. Sadlej, J. Mol. Struct.: THEOCHEM, 1988, 180, 65.

29 A. M. Sapse and K. Raghavachari, Chem. Phys. Lett., 1989, 158, 213.

30 S. Scheiner, J. Mol. Struct.: THEOCHEM, 1989, 200, 117.

31 Y. Bouteiller, Z. Latajka, H. Ratajczak and S. Scheiner, J. Chem. Phys., 1991, 94, 2956.

32 B. S. Ault and G. C. Pimental, J. Phys. Chem., 1975, 79, 621.

33 J-L. M. Abboud, M. Yáñez, J. Elguero, D. Liotard, M. Essefar, M. El Mouhtadi and R. W. Taft, New J. Chem., 1992, 16, 739.

34 R. J. Blint, J. Electrochem. Soc., 1995, 142, 696.

35 G. D. Smith, R. L. Taffe and H. Partridge, J. Phys. Chem. A, 1997, 101, 1705 .

36 R. L. Woodin and J. L. Beauchamp, J. Am. Chem. Soc., 1978, 100, 501.

37 D. Becke, J. Chem. Phys., 1993, 98, 5648.

38 C. Lee, W. Yang and R. G. Parr, Phys. Rev. B, 1988, 37, 785.

39 F. Boys and F. Bernardi, Mol. Phys., 1970, 19, 553.

40 P. I. Nagy, D. A. Smith, G. Alagona and C. Ghio, J. Phys. Chem., $1994,98,486$

41 E. D. Glendening, A. E. Reed, J. E. Carpenter and F. Weinhold, NBO Version 3.1.

42 M. J. Frisch, G. W. Trucks, H. B. Schlegel, P. M. W. Gill, B. G. Johnson, M. A. Robb, J. R. Cheeseman, T. Keith, G. A. Petersson, J. A. Montgomery, K. Raghavachari, M. A. Al-Laham, V. G. Zakrzewski, J. V. Ortiz, J. B. Foresman, C. Y. Peng, P. Y. Ayala, W. Chen, M. W. Wong, J. L. Andres, E. S. Replogle, R. Gomperts, R. L. Martin, D. J. Fox, J. S. Binkley, D. J. Defrees, J. Baker, J. J. P. Stewart, M. Head-Gordon, C. Gonzalez and J. A. Pople, GAUSSIAN 94, Revision B.2, Gaussian, Pittsburg PA, 1995.

43 A. C. Legon and D. J. Millen, J. Am. Chem. Soc., 1987, 109, 356.

44 R. K. Thomas, Proc. R. Soc. London A, 1971, 322, 137.

45 J. A. Platts, S. T. Howard and B. R. F Bracke, J. Am. Chem. Soc., 1988, 118, 2726.

46 A. E. Reed, F. Weinhold, L. A. Curtiss and D. A. Pochatko, J. Chem. Phys., 1986, 84, 5687. 